\title{
Referans Evapotranspirasyon Hesabında Kullanılacak Android Tabanlı Bir Uygulamanın Geliştirilmesi
}

\author{
Neslihan Bircan ${ }^{1}$ iD \\ Ünal Kızıl $^{2 * i D}$ \\ ${ }^{1}$ Çanakkale Onsekiz Mart Üniversitesi, Lisans Üstü Eğitim Enstitüsü, Tarımsal Yapılar ve Sulama, A.B.D. Çanakkale \\ ${ }^{2}$ Çanakkale Onsekiz Mart Üniversitesi, Ziraat Fakültesi, Tarımsal Yapılar ve Sulama Bölümü, Çanakkale \\ * Sorumlu yazar: unal@ comu.edu.tr
}

Geliş Tarihi: 13.07.2021

Kabul Tarihi: 02.11.2021

\section{$\ddot{\mathbf{O} z}$}

Akıllı cihaz olarak adlandırılan tablet ve cep telefonlarında en yaygın kullanılan Android işletim sistemleri üzerinde çalışabilen ve referans bitki su tüketimi ya da referans evapotranspirasyon $\left(\mathrm{ET}_{0}\right)$ hesabı yapan bir uygulama geliştirilmiştir. Geliştirilen uygulama ile 17 adımda hesaplanan, birçok meteorolojik veriye ve tablo değerine ihtiyaç duyulan $\mathrm{ET}_{0}$ değeri, sadece il ve enlem derecesi seçimi yapılarak kolayca hesaplanabilmektedir. Meteorolojik verilerin seçilen il bilgisine bağlı olarak, programlama ara yüzü olarak da bilinen API bağlantısı gerçekleştirilerek online veri tabanından çekilmesi sağlanmıştır. Akıllı cihazın GPS sensörü ile elde edilen enlem derecesine göre aylık bazı tablo değerleri regresyon eşitlikleri kullanılarak kodlanmıştır. Uygulama Google'ın desteklediği online, sürükle-bırak tekniğine göre kodlama yapılabilen MIT App Inventor 2 platformunda geliştirilmiştir. Başka sensör sistemleriyle bluetooth ve GSM şebekesi üzerinden bağlantı kablosuz bağlantı kurabilen bir cihaz geliştirilmiştir. Geliştirilen cihaz sulama sistemlerinin otomasyonunda kullanılabilecek, veri transfer ve depolama özelliklerine sahip dinamik bir cihazdır. $\mathrm{Bu}$ çalışmada uygulamanın geliştirilme aşama ve yöntemleri tartışılmış, örnek bir çözüm hem uygulama ile hem de el ile yapılarak uygulamanın genel performansı değerlendirilmiştir.

Anahtar Kelimeler: Sulama, Akıllı Cihaz, Evapotranspirasyon, Android İşletim Sistemi

\section{Development of an Android-based Application to be used in the Calculation of Reference Evapotranspiration}

\section{Abstract}

An application that calculates reference plant water consumption or reference evapotranspiration has been developed that can run on Android operating system based tablets and mobile phones, called smart devices. With the developed application, the reference plant water consumption value, which is calculated in 17 steps and needs many meteorological data and table values, can be easily calculated by simply selecting the province and latitude. Depending on the selected province information, the meteorological data are retrieved from the online database by making an application programing interface (API) connection. According to the latitude obtained with the GPS sensor of the smart device, some monthly table values were coded using regression equations. The application was developed on the MIT App Inventor 2 platform, which is supported by Google and can be coded according to the drag-and-drop technique. With the application, which has the ability to connect with other sensors via bluetooth and GSM networks, a dynamic tool with data transfer and storage function that can be used in the automation of irrigation systems has been developed. In this study, the development stages and methods of the application were discussed, and a sample solution was evaluated both by application and by hand, and the overall performance of the application was discussed.

Keywords: Irrigation, Smart Device, Evapotranspiration, Android Operating System

\section{Giriş}

Hidrolojik döngünün en önemli parametrelerinden biri olan evapotranspirasyon (ET) ya da bitki su tüketimi, sulama sistemlerinin projelendirilmesi, sulama programlarının hazırlanması ve hidrolojik çalışmalarda yoğun şekilde kullanılmaktadır. Bu nedenle ET’nin doğru tahmin edilmesi su dengesi, çevrenin korunması, sulama sistemlerinin tasarımı ve su kaynakları yönetimi için önemlidir. Bitkisel üretimde yetersiz ve gereğinden fazla uygulanan sulama toprağ 1 , ürünü, tarımsal üretim girdisini ve verimi olumsuz yönde etkiler. Kaliteli ve yüksek verimde ürün elde edilebilmesi için bitki su tüketimi dikkate alınarak en uygun sulama programının oluşturulması gerekir. 
Evapotranspirasyon, toprak yüzeyinden olan buharlaşma (evaporasyon) ile bitki tarafindan yapılan terleme (transpirasyon) sonucu atmosfere aktarılan toplam su buharı olarak da tanımlanabilir (Karaca ve ark., 2017a; Karaca ve ark., 2017b). Doğrudan lizimetreler ile belirlenebildiği gibi iklimsel veriler kullanarak çeşitli ampirik yöntemlerle tahmin de edilebilir. Lizimetreler ET tahmininde en doğru ve güvenilir yöntemlerdir ancak uygulaması zor ve oldukça pahalı bir yöntemdir (Karaca ve ark., 2017b). Dolayısıyla, ET hesabında kullanılan eşitlikleri, referans bir bitkinin evapotranspirasyon $\left(\mathrm{ET}_{0}\right)$ değerlerini kullanarak standartlaştırma fikri ortaya atılmıştır (Jensen, 1968; Jensen ve ark., 1971).

Penman (1948), enerji dengesi ve kütle transferlerini temel alarak farklı eşitlikler geliştirmiştir. Bu eşitlikler yıllar içerisinde birçok araştırmacı tarafından geliştirilerek bazı sabitelerin kullanımıyla hesaplanabileceği şekle getirilmiştir. Penman (1948) geliştirdiği yöntemle güneşlenme, sıcaklık, nem ve rüzgâr hızı gibi iklim değerlerini esas alarak açık su yüzeyinden gerçekleşecek buharlaşmayı formüle etmiştir. Monteith (1976) bu yöntemi aerodinamik ve yüzey direnci faktörlerini de göz önüne alınarak bitkilerden olan terlemeyi de tahmin eden daha kapsamlı bir yönteme dönüştürmüştür. Bu yöntem FAO (1990) tarafindan, birçok uzman bir araya getirilerek FAO PenmanMonteith adıyla son halini almış ve potansiyel su tüketimi yerine "referans bitki su tüketimi" kavramı ile FAO56-PM olarak kullanılmaya başlanmıştır (Allen ve ark., 1994; Allen ve ark., 1998). Söz konusu hesaplama birden fazla parametreye bağlı veriler kullanılarak karmaşı işlemlerle yapılır. $\mathrm{Bu}$ hesaplamayı kolaylaştırabilmek için birçok bilgisayar programı geliştirilmiştir.

Günümüzde bilgisayar ve yazılım teknolojilerinin sağladığı imkânlar ile oldukça zor olan ET hesaplamaları yapılabilmektedir. Bu yazılımlardan bazıları IRSIS, BUDGET, CROPWAT ve AQUACROP gibi içerisinde sulama programlama olanağı bulunan çeşitleriyle kullanılmaktadır (Raes ve ark. 1988; Raes ve ark. 2006; FAO, 2009).

Özellikle bilgi ve iletişim teknolojileri hayatın her alanında olduğu gibi tarım alanında da yaygın bir kullanım alanı bulmaktadır. Böylece tarımsal uygulamaların daha hassas ve sistematik hale gelmesi sağlanmaktadır. Günümüzde yoğun bir şekilde kullandığımız GSM ve internet ile entegre Android ve IOS teknolojilerine dayalı hizmetler, bitkisel ve hayvansal ürünlerin üretilmesi, kalite ve verimliliklerinin yükseltilmesi, uygun koşullarda korunması, işlenip değerlendirilmesi ve pazarlaması süreçlerinde mühendislere destek sağlamaktadır. Sulama mühendisliğinde de yeni yaklaşımlar ve teknolojik değişiklikler, mobil ağlar ve uygulamaları kullanmayı zorunlu kılmaktadır. Bu bağlamda yapılacak mobil uygulama çalışmaları ve yeni teknolojilerin uygulanması, iş yükünü önemli ölçüde azaltacağı gibi suyun daha etkin kullanımını sağlayacaktır. Bu çalışmada, $\mathrm{ET}_{0}$ hesabı yapan Android tabanlı akıllı cihazlarda çalışabilecek kullanımı kolay, herkes tarafından ulaşılabilecek bir uygulama geliştirilmek hedeflenmiştir. Geliştirilen uygulama sayesinde sulama programı oluşturmada kullanılacak olan hesaplama adımları arazi koşullarında dahi hızlı ve pratik bir şekilde yapılabilir hale gelmiştir.

\section{Materyal ve Yöntem}

\section{Android Programlama}

Uygulama geliştirmede kullanılan platform Google tarafından çıkarılmış ve Massachusetts Institute of Technology (MIT) tarafından geliştirilerek MIT App Inventor adıyla kullanıma sunulmuştur. Daha sonra güncellenerek MIT App Inventor 2 versiyonu yayınlanmış olan platform ücretsiz bir uygulama geliştirme aracı sunmaktadır. Kullanıcıların Android işletim sistemi için blok kodlama yöntemiyle uygulama geliştirmesine olanak sağlayan (Anonim, 2015) platform MIT App Inventor 2 web tarayıcısını kullanmaktadır.

Android işletim sistemi Linux çekirdeğine dayanır, yani uygulama yalıtımı, dosya sistemi ve güvenlik kuralları Linux’a özgüdür (Pocatilu, 2011). Android uygulama dosyaları uygulama için tüm kaynakları içeren apk uzantısı ile paketlenmiş dosyalar olarak sunulmaktadır (Burnette, 2010). Android uygulamaları Java programlama dili ile yazılmakta ancak standart Java Sanal Makinesi (JVM) kullanılarak yürütülmemektedir. Bunun yerine Google, Dalvik VM adında özel bir sanal makine oluşturmuştur. Burada Java sadece bayt kodunu dönüştürmek ve yürütmekten sorumludur (Holla ve ark. 2012). 


\section{Penman-Monteith Yöntemini ile ET $_{\mathbf{0}}$ Hesaplanması}

Çalışmanın temelini oluşturan ve FAO tarafindan modifiye edilmiş olan Penman-Monteith eşitliği aşağıda verilmiştir (Eşitlik 1). Eşitlikteki parametreler konumsal ve mevsimsel bilgilere dayalı meteorolojik verilerdir. Dolayısıyla, $\mathrm{ET}_{0}$ hesabının en önemli aşaması söz konusu verilere sahip olabilmektir. Uygulamanın geliştirilmesinde, birçok çizelgeden ve meteorolojik veri kaynaklarından elde edilen bu verilerin kısa sürede elde edilmesi ve çizelge değerlerinin regresyon eşitlikleri sayesinde belirlenmesi başlıca iş yükünü oluşturmuştur.

$\mathrm{ET}_{0}=\frac{\delta}{\delta+\gamma^{*}}\left(R_{n}-G\right) \frac{1}{\lambda}+\frac{\gamma}{\delta+\gamma^{*}} \frac{900}{(T+275)} u_{2}\left(e_{\alpha} e_{d}\right)$

Eşitlikte kullanılan parametreler ve onların hesaplamasında kullanılan yardımcı eşitlikler ise şöyledir (Eşitlik 2-11);

$$
\begin{aligned}
& \delta=\frac{4098 e_{a}}{(T+237.3)^{2}} \\
& \lambda=2.501-\left(2.361 \times 10^{-3}\right) T \\
& \gamma=0.0016286 \frac{p}{\lambda} \\
& \gamma^{*}=\gamma\left(1+0.34 u_{2}\right) \\
& R_{n}=R_{n s}-R_{n l} \\
& R_{n s}=0.75 R_{s} \\
& R_{n l}=2.451 f(T) f\left(e_{d}\right) f\left(\frac{n}{N}\right) \\
& R_{s} \cong\left(0.25+0.50 \frac{n}{N}\right) R_{a} \\
& e_{d}=e_{a} \frac{R H}{100} \\
& u_{2}=u_{z}\left(\frac{2}{z}\right)^{0.2}
\end{aligned}
$$

Eşitliklerde;

$\mathrm{ET}_{0}=$ Referans evapotranspirasyon ( $\left.\mathrm{mm} / \mathrm{gün}\right)$,

$\delta=$ Buhar basıncı eğrisinin eğimi $\left(\mathrm{kPa} /{ }^{\circ} \mathrm{C}\right)$,

$\gamma^{*}=$ Modifiye psikometrik sabite $\left(\mathrm{kPa} /{ }^{\circ} \mathrm{C}\right)$,

$\gamma=$ Psikrometrik sabit $\left(\mathrm{kPa} /{ }^{\circ} \mathrm{C}\right)$,

$\mathrm{P}=$ Atmosfer basinc1 $(\mathrm{kPa})$,

$\mathrm{R}_{\mathrm{n}}=$ Bitki yüzeyindeki net radyasyon $\left(\mathrm{MJ} / \mathrm{m}^{2} /\right.$ gün$)$,

$\mathrm{R}_{\mathrm{a}}=$ Atmosferin diş yüzeyine ulaşan radyasyon $\left(\mathrm{MJ} / \mathrm{m}^{2} / \mathrm{gün}\right)$,

$\mathrm{R}_{\mathrm{s}}=$ Yeryüzüne ulaşan kısa dalgalı radyasyon $\left(\mathrm{MJ} / \mathrm{m}^{2} /\right.$ gün$)$,

$\mathrm{R}_{\mathrm{ns}}=$ Kisa dalgalı net radyasyon $\left(\mathrm{MJ} / \mathrm{m}^{2} /\right.$ gün$)$,

$\mathrm{R}_{\mathrm{nl}}=$ Uzun dalgalı net radyasyon $\left(\mathrm{MJ} / \mathrm{m}^{2} /\right.$ gün$)$,

$\mathrm{F}(\mathrm{T})=$ Sicaklık fonksiyonu,

$\mathrm{f}\left(\mathrm{e}_{\mathrm{d}}\right)=$ Buhar basinc fonksiyonu,

$\mathrm{e}_{\mathrm{d}}=$ Ortalama hava sıcaklığındaki gerçek buhar basıncı $(\mathrm{kPa})$,

$\mathrm{e}_{\mathrm{a}}=$ Ortalama hava sıcaklığındaki doygun buhar basınc1 $(\mathrm{kPa})$,

$\mathrm{f}(\mathrm{n} / \mathrm{N})=$ Güneşlenme oranı fonksiyonu,

$\mathrm{T}=$ Sicaklik $\left({ }^{\circ} \mathrm{C}\right)$,

$\mathrm{u}_{2}=2 \mathrm{~m}$ yükseklikteki ortalama rüzgâr hızı $(\mathrm{m} / \mathrm{s})$,

$\mathrm{n}=$ Güneşlenme süresi (h),

$\mathrm{N}=$ Olası azami güneşlenme süresi (h),

$\mathrm{G}=$ Topraktaki ısı akımı (MJ $/ \mathrm{m}^{2} /$ gün $)$

$\Lambda=$ Buharlaşma gizli 1sısı, (MJ $/ \mathrm{kg}$ ) (Ortalama bir değer olarak $2.45 \mathrm{MJ} / \mathrm{kg}$ alınabilir),

$\mathrm{u}_{\mathrm{z}}=$ Rüzgar hızının ölçüldüğü yükseklik (m),

RH= Ortalama bağıl nem (\%).

Hesaplamaları yapmak için bölgeye ait iklim verileri ve bazı çizelge değerlerinin kullanılabilmesi için enlem derecesi gibi verilere ihtiyaç duyulmaktadır. Ele alınan verilerin çizelgelerde kullanılmasıyla eşitliklerde kullanılacak parametreler hesaplanmaktadır. 


\section{Eşitlikte Kullanılan Parametrelerin Elde Edilmesi}

Uygulama ile meteorolojik verilere göre $\mathrm{ET}_{0}$ ' in hızlıca ve en az veri girişi sağlayarak hesaplanması hedeflenmektedir. Bu amaçla, gerekli bazı veriler API (Uygulama Programlama Ara yüzü) kullanılarak online meteorolojik veri sitesinden çekilmektedir. Gerekli verilerin bu şekilde elde edilebilmesi için hesaplamanın yapıldığ 1 ilin seçilmesi gerekmektedir. Seçilen il referans alınarak gerekli günlük meteorolojik veriler otomatik olarak kaynak siteden ekrana getirilmektedir. Hesaplamalarda kaynak siteden çekilen meteorolojik veriler ortalama günlük sıcaklık (C), atmosfer basınc1 $(\mathrm{kPa})$, ortalama günlük bağıl nem $(\%)$, ortalama rüzgâr hızı $(\mathrm{m} / \mathrm{s})$ ve günlük güneşlenme süresi (saat)' dir.

Kullanılan diğer parametreler ise literatürde sunulmuş olan çizelgelerden elde edilmektedir (Kanber, 1999). Çizelgelerdeki değerlerin bir kısmı API kullanılarak elde edilmiş olan günlük ortalama sıcaklık değerine göre hesaplanmaktadır. Bir kısmı ise hesaplamanın yapıldığı konumun enlem derecesine ve aya göre belirlenmektedir. $\mathrm{Bu}$ aşamada enlem derecesinin bilinmesi gerekmektedir. Enlem derecesi belirlenirken ya akıllı cihazın (telefon veya tablet) GPS sensörü kullanılarak daha gerçekçi bir değer elde edilmekte ya da her ili temsilen uygulamanın veri tabanına girilmiş olan değer seçilebilmektedir. Ay ise kullanılan akıllı cihazın tarih bilgisinden kodlama ile otomatik olarak elde edilmektedir. Uygulamanın hesaplama aşamalarında kullanılan çizelgelerden elde edilen veriler ve bu verilerin nasıl elde edildiği aşağıda verilmiştir (Çizelge 1). Diğer parametreler de yukarıda verilmiş olan eşitlikler kullanılarak hesaplanmıştır.

Çizelge 1. $\mathrm{ET}_{0}$ hesabında kullanılan veriler ve elde edilme yöntemleri

\begin{tabular}{|c|c|c|}
\hline Parametre & Sembol & Kaynak \\
\hline $\begin{array}{l}\text { Ortalama hava } \text { sicaklığındaki } \\
\text { doygun buhar basıncı }(\mathrm{kPa})\end{array}$ & $\mathrm{e}_{\mathrm{a}}$ & $\begin{array}{l}\text { Ortalama günlük sıcaklığa bağlı olarak gerekli } \\
\text { çizelgeden }\end{array}$ \\
\hline Olası azami güneşlenme süresi (h) & $\mathrm{N}$ & $\begin{array}{l}\text { Hesaplamanın yapıldığı ay ve enlem } \\
\text { derecesine bağlı olarak gerekli çizelgeden }\end{array}$ \\
\hline $\begin{array}{l}\text { Atmosferin dış yüzeyine ulaşan } \\
\text { radyasyon }\left(\mathrm{MJ} / \mathrm{m}^{2} / \text { gün }\right),\end{array}$ & $\mathrm{R}_{\mathrm{a}}$ & $\begin{array}{l}\text { Hesaplamanın yapıldığı ay ve enlem } \\
\text { derecesine bağlı olarak gerekli çizelgeden }\end{array}$ \\
\hline Sicaklik fonksiyonu & $f(T)$ & $\begin{array}{l}\text { Ortalama günlük sıcaklığa bağlı olarak gerekli } \\
\text { çizelgeden }\end{array}$ \\
\hline Buhar basincı fonksiyonu & $f\left(e_{d}\right)$ & $\begin{array}{l}\text { Ortalama hava sicaklığındaki gerçek buhar } \\
\text { basınc1 }\left(e_{d}\right) \text { için çizelgeden }\end{array}$ \\
\hline Güneşlenme oranı fonksiyonu & $\mathrm{f}(\mathrm{n} / \mathrm{N})$ & $\mathrm{n} / \mathrm{N}$ oranına bağlı olarak gerekli çizelgeden \\
\hline
\end{tabular}

Gerekli verileri çizelgeleri kullanarak belirleyebilmek için regresyon eşitlikleri hazırlanmıştır. Aşağıda ortalama günlük ortalama sıcaklığın $(\mathrm{T})$ bir fonksiyonu olarak doygun buhar basincının $\left(\mathrm{e}_{\mathrm{a}}\right)$ belirlendiği regresyon eşitliği ve ilgili $\mathrm{R}^{2}$ değeri verilmiştir.

$\mathrm{e}_{\mathrm{a}}=0,0038 \mathrm{~T}^{2}+0,0027 \mathrm{~T}+0,7614 \quad\left(\mathrm{R}^{2}=0,999\right)$

Olası azami güneşlenme süresi $(\mathrm{N})$ enlem derecesine (ED) göre her bir ay için ayrı ayrı geliştirilmiş regresyon eşitlikleriyle belirlenmiştir. Aylık olası azami güneşlenme süresini veren regresyon eşitlikleri ve $\mathrm{R}^{2}$ değerleri aşağıda verilmiştir (Çizelge 2).

Benzer şekilde atmosferin dış yüzeyine ulaşan radyasyon $\left(\mathrm{R}_{\mathrm{a}}\right)$ değeri de her ay için ve enlem derecesine bağlı olarak geliştirilen regresyon eşitlikleriyle hesaplanmıştır (Çizelge 3).

Sicaklık fonksiyonu $\mathrm{f}(\mathrm{T})$ da günlük ortalama sıcaklığın bir fonksiyonu olarak geliştirilmiş regresyon eşitliği kullanılarak aşağıdaki eşitlikle hesaplanmıştır.

$$
\mathrm{f}(\mathrm{T})=0,1979 \mathrm{~T}+10,77 \quad \mathrm{R}^{2}=0,997
$$

Buhar basıncı fonksiyonu $\left(\mathrm{f}_{\mathrm{ed}}\right)$ ortalama hava sıcaklığındaki gerçek buhar basıncı $\left(\mathrm{e}_{\mathrm{d}}\right)$ için verilmiş çizelge değerlerinin regresyon eşitliğine dönüştürülmesiyle aşağıdaki regresyon eşitliğiyle hesaplanmıştır.

$$
\mathrm{f}_{\mathrm{ed}}=0,0057 \mathrm{e}_{\mathrm{d}}^{2}-0,0754 \mathrm{e}_{\mathrm{d}}+0,2731 \quad \mathrm{R}^{2}=0,991
$$

Günlük güneşlenme süresinin (n) olası azami günlük güneşlenme süresi $(\mathrm{N})$ oranına $(\mathrm{GO})$ bağlı olarak da güneşlenme oranı fonksiyonu için de aşağıdaki regresyon eşitliği geliştirilmiş̧tir.

$$
\mathrm{f}(\mathrm{n} / \mathrm{N})=0,9008 \mathrm{GO}+0,1021 \quad \mathrm{R}^{2}=0,999
$$


Görüldüğü üzere kullanıcının sadece hesaplamanın yapıldığı ili ve enlem derecesini belirlediği basit iki adımda gerekli tüm veriler ve hesaplamalar birkaç saniye içerisinde otomatik olarak yapılabilmektedir.

Çizelge 2. Aylara göre olası azami güneşlenme süresi (N) için regresyon eşitlikleri

\begin{tabular}{llll}
\hline Eşitlik & Ay & $\mathrm{R}^{2}$ & Eşitlik No \\
\hline $\mathrm{N}=-0,0828 \mathrm{ED}+12,922$ & Ocak & 0,989 & 13 \\
$\mathrm{~N}=-0,0449 \mathrm{ED}+12,494$ & Şubat & 0,968 & 14 \\
$\mathrm{~N}=11.9$ & Mart & 1,000 & 15 \\
$\mathrm{~N}=0,0379 \mathrm{ED}+11,773$ & Nisan & 0,984 & 16 \\
$\mathrm{~N}=0,0803 \mathrm{ED}+11,193$ & Mayıs & 0,998 & 17 \\
$\mathrm{~N}=0,1 \mathrm{ED}+11$ & Haziran & 1,000 & 18 \\
$\mathrm{~N}=0,0893 \mathrm{ED}+11,189$ & Temmuz & 0,987 & 19 \\
$\mathrm{~N}=0,0562 \mathrm{ED}+11,513$ & Ağustos & 0,988 & 20 \\
$\mathrm{~N}=0,0163 \mathrm{ED}+11,877$ & Eylül & 0,856 & 21 \\
$\mathrm{~N}=-0,0335 \mathrm{ED}+12,501$ & Ekim & 0,979 & 22 \\
$\mathrm{~N}=-0,0651 \mathrm{ED}+12,565$ & Kasım & 0,995 & 23 \\
$\mathrm{~N}=-0,0936 \mathrm{ED}+13,037$ & Aralı & 0,998 & 24 \\
\hline
\end{tabular}

Çizelge 3. Aylara göre atmosfer dış yüzeyine ulaşan radyasyon $\left(R_{a}\right)$ için regresyon eşitlikleri

\begin{tabular}{llll}
\hline Eşitlik & Ay & $\mathrm{R}^{2}$ & Eşitlik No \\
\hline $\mathrm{R}_{\mathrm{a}}=-0,6042 \mathrm{ED}+39,769$ & Ocak & 0,999 & 25 \\
$\mathrm{R}_{\mathrm{a}}=-0,0726 \mathrm{ED}^{2}+4,3439 \mathrm{ED}-32,354$ & Şubat & 0,927 & 26 \\
$\mathrm{R}_{\mathrm{a}}=-0,4443 \mathrm{ED}^{2}+45,644$ & Mart & 0,996 & 27 \\
$\mathrm{R}_{\mathrm{a}}=-0,2729 \mathrm{ED}+45,758$ & Nisan & 0,982 & 28 \\
$\mathrm{R}_{\mathrm{a}}=-0,0929 \mathrm{ED}+43,571$ & Mayis & 0,922 & 29 \\
$\mathrm{R}_{\mathrm{a}}=44,20$ & Haziran & 1,000 & 30 \\
$\mathrm{R}_{\mathrm{a}}=40,91$ & Temmuz & 1,000 & 31 \\
$\mathrm{R}_{\mathrm{a}}=-0,0165 \mathrm{ED}^{2}+1,1041 \mathrm{ED}+19,473$ & Ağustos & 0,981 & 32 \\
$\mathrm{R}_{\mathrm{a}}=-0,3629 \mathrm{ED}+45,151$ & Eylül & 0,999 & 33 \\
$\mathrm{R}_{\mathrm{a}}=-0,5443 \mathrm{ED}+45,244$ & Ekim & 0,991 & 34 \\
$\mathrm{R}_{\mathrm{a}}=-0,6016 \mathrm{ED}+41,227$ & Kasim & 0,999 & 35 \\
$\mathrm{R}_{\mathrm{a}}=-0,63 \mathrm{ED}+39,171$ & Aralı & 0,999 & 36 \\
\hline
\end{tabular}

\section{Uygulama Ara Yüzü Ve Kullanılması}

Uygulamanın kullanıc1 ara yüzüne ait ekran görüntüsü Şekil 1'de verilmiştir. Hesaplama adımları yukarıdan aşağıya doğru takip edilmektedir. İlk aşamada hesaplama yapılacak il ve o ile ait enlem derecesinin seçilmesi gerekmektedir. Burada "Mevcut konum için enlem al" seçeneği tercih edildiğinde mevcut bulunulan konumun enlem derecesi cihazın GPS sensörü marifetiyle otomatik olarak ekrana getirilmektedir. Eğer başka bir konum için hesaplama yapılacaksa "Başka bir il için enlem al" seçeneği tercih edilmelidir. Bu seçenek tercih edildiğinde "Başka Bir İl Seçin" düğmesine basılarak hesaplamanın yapılacağı il ve o ili temsil eden enlem derecesi uygulamanın veri tabanından seçilmektedir. Şayet hesaplama yapılacak konumun enlem derecesi biliniyorsa doğrudan ekrandaki Enlem derecesi veri giriş hanesine el ile de yazılabilir. 


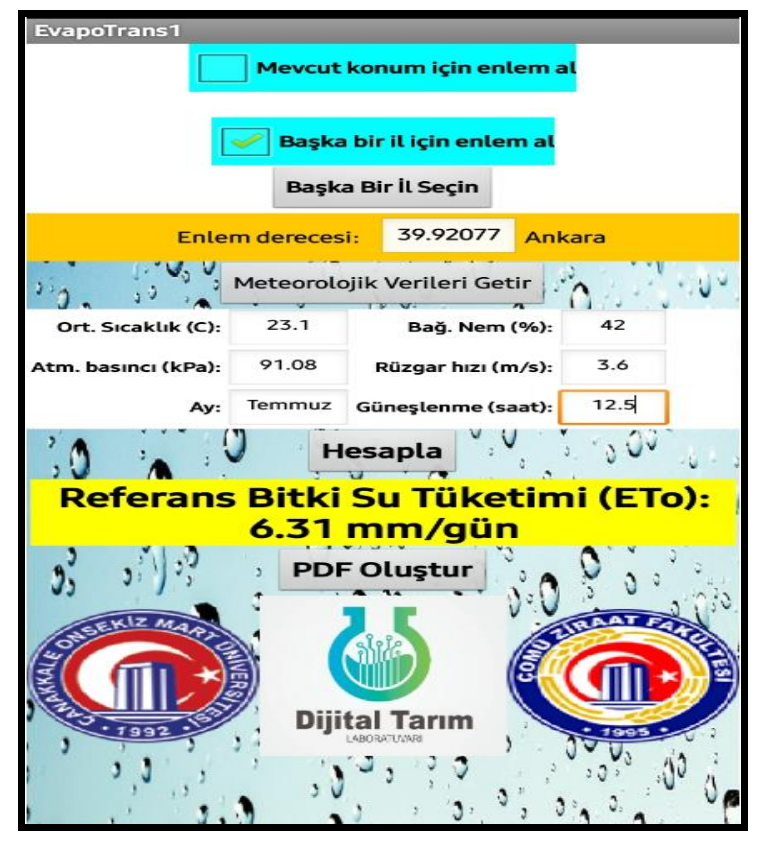

Şekil 1. Uygulama kullanıcı ara yüzü

$\mathrm{Bu}$ şekilde konum ve il verisi seçildikten sonra yapılması gereken şey o güne ait meteorolojik verilerin sağlanmasıdır. Bu ise "Meteorolojik Verileri Getir" düğmesine basıldığında API bağlantısı üzerinden otomatik olarak gerçekleşmektedir. Burada da yine alternatif olarak el ile veri girişi yapılarak başka bir güne ait veriler hesaplamada kullanılabilmektedir. Bu aşamadan sonra "Hesapla" düğmesine basılarak o gün için $\mathrm{ET}_{0}$ hesaplanmaktadır. Uygulamanın sağladığı diğer bir avantaj ise el ile çözüm yapıldığında toplam 17 adımda gerçekleşen hesaplamanın bütün adımlarını detaylı bir rapor olarak da hazırlayabilmesidir. Bunun için "PDF Oluştur" düğmesine basmak yeterlidir. Açılacak olan yeni ekranda bütün aşamalar ve kullanılan parametreler detaylı bir rapor halinde hazırlanacaktır. Açılan bu rapor sayfasının üstünde bulunan "PDF Paylaş" düğmesine basılarak da hazırlanmış olan rapor pdf formatında elektronik posta yoluyla ya da WhatsApp mesaj1 eklentisi olarak paylaşılabilmektedir. Bununla ilgili örnek bir sonraki bulgular ve tartışma bölümünde verilecektir. Geliştirilmiş olan uygulamanın çalışma prensibinin daha iyi anlaşılabilmesi için akış diyagramı Şekil 2 'de verilmiştir.

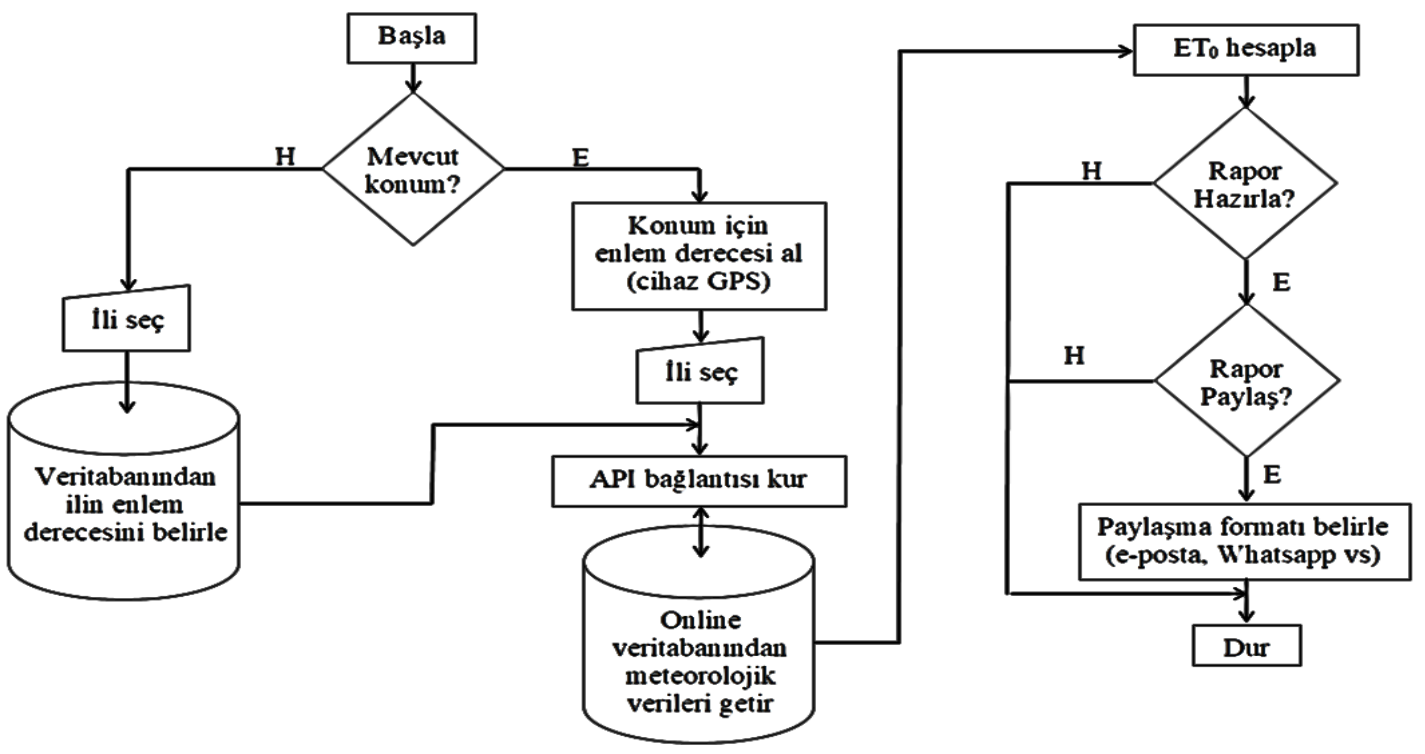

Şekil 2. Uygulama akış diyagramı 


\section{Bulgular ve Tartışma}

Referans bitki su tüketimi hesabında kullanılan Penman-Monteith yöntemi ampirik eşitliklere dayanan hesaplama teknikleri arasında en yaygın kullanıma sahip olan yöntemlerden birisidir. Dolayısıyla söz konusu yöntemi esas alarak geliştirilecek yazılım ve/veya uygulamalarda esas incelenmesi ve tartışılması gereken noktalar geliştirilen söz konusu uygulama/yazılımların kullanım kolaylığı, erişilebilirliği, hesaplamalarda olabilecek muhtemel hatalar ve ileride farklı amaçlara uygun olarak modifiye edilebilme ya da başka bir ifadeyle sağladığı esneklikler olmalıdır. Bu anlamda günlük ya da tahminlenen meteorolojik veriler kullanılabilir. Burada meteorolojik verilerin elde edilebilirliği önemli rol oynamaktadır. Ballesteros ve ark. (2016) bu yöntemde kullanılan meteorolojik verileri tahmin esasına dayalı bir yazılım geliştirmişlerdir. Bu çalışmada geliştirilen uygulamanın performansı çok farklı örneklerle test edilerek sinanmıştır.

Yukarıda da açıklandığı üzere geliştirilen uygulama akıllı bir telefon kullanabilme becerisine sahip herkes tarafından rahatlıkla kullanılabilecek kolaylıktadır. Sadece 2 veri seçimi (il ve enlem) ile $\mathrm{ET}_{0}$ hesaplanabilmektedir. Burada kullanım aşamasında meteorolojik verilerin çekilmesi ve mevcut konum için enlem derecesinin alınması konusunda dikkat edilmesi gereken noktalar vardır. API bağlantısı üzerinden meteorolojik verilerin alınabilmesi için uygulamanın çalıştığı cihazın internet bağlantısı sağlaması gerekmektedir. Hesaplama eğer mevcut bulunulan konum için yapılacaksa ve eğer iç ortamda iken enlem derecesi bilgisi alınacaksa cihazın GPS sensörünün enlem derecesi bilgisini alması anında olmayabilir ve yaklaşı 20-30 saniyelik bir gecikme söz konusu olabilir. $\mathrm{Bu}$ yüzden mümkünse enlem derecesinin açı havada alınması önerilir. Kapalı ortamda alınacaksa pencere kenarına giderek ve biraz hareket ederek bu süre kısaltılabilir.

Söz konusu hesaplamaları yapmak amacıyla geliştirilmiş birçok yazılım mevcuttur. Ancak bunlar genellikle masaüstü bilgisayarlarda çalışmaktadır. Gocic ve Trajkovic (2010) Windows tabanlı ve sınırlı veriyle $\mathrm{ET}_{0}$ hesaplayan kullanımı kolay bir yazılım geliştirmişlerdir. Ancak, günümüzde akıllı cihazlarda çalışan uygulamalara gereksinim giderek artmaktadır. $\mathrm{Bu}$ anlamda geliştirilen uygulamanın akıllı cihazlarda kullanımı oldukça önemlidir. Geliştirilen uygulama Google Play Store üzerinde yayınlanacak ve böylece kullanıcılar kolay bir şekilde uygulamaya ulaşabileceklerdir. Diğer bir yöntem ise MIT App Inventor 2'de geliştirme işlemi tamamlandıktan sonra apk uzantılı dosyanın USB bağlantısı üzerinden ya da elektronik posta ile kurulumun yapılacağı cihaza gönderilip standart kurulum aşamalarının takip edilmesidir. Bu çalışmada geliştirilen uygulama sadece 6,05 $\mathrm{MB}$ boyutunda olup mail ile ya da diğer veri taşıma yöntemleriyle rahatlıkla taşınabilmektedir. $\mathrm{Bu}$ bağlamda kolay ve hızlı bir şekilde erişim ve kurulum sağlanarak kullanıma geçilebilecektir.

Uygulamanın kodlanması aşamasında söz konusu formüllerin ve geliştirilen regresyon eşitliklerinin doğru bir şekilde girilip girilmediğini görebilmek için örnek bir hesaplama hem el ile hem de uygulama ile çözülmüştür. Söz konusu örnek çözüm için hesaplamanın yapıldığı il ve gerekli diğer veriler aşağıda özetlenmiştir (Çizelge 4).

Çizelge 4. Örnek hesaplamanın yapıldığı konum ve diğer koşullar

İl Ankara

Enlem derecesi (ED):

$39^{\circ} 57^{\prime}$

Hesaplamanın yapıldı̆̆ 1 ay:

Temmuz

Ortalama günlük sıcaklık (T):

$23,1{ }^{\circ} \mathrm{C}$

10 M'de ölçülen rüzgâr hızı $\left(\mathrm{u}_{10}\right)$ :

$3,6 \mathrm{~m} / \mathrm{s}$

Ortalama günlük bağıl nem (RH):

$\% 42$

Günlük güneşlenme süresi (n):

12 h 27 dak.

Atmosfer basinc1 (P):

$91,08 \mathrm{kPa}$

Uygulama başka bir il, ay ve bilinen meteorolojik veriler için çalıştırılacağından, bütün veriler el ile girilmiş, enlem derecesi ise Ankara için cihazın veri tabanından çekilmiştir. Çizelge 4'teki verilerin el ile girilmiş hali yukarıda Şekil 1'de verilmiştir. Yine aynı şekilde girilen verilere karşın 
hesaplanan $\mathrm{ET}_{0}$ '1n $6,31 \mathrm{~mm} /$ gün olduğu görülmektedir. Bu bağlamda sonucun doğruluk derecesinin tartışılabilmesi için gerekli hesaplama el ile yapılmış, işlem aşamaları ve sonuç Çizelge 5 'te verilmiştir.

Çizelge 5. Örnek hesaplamanın el ile çözümü

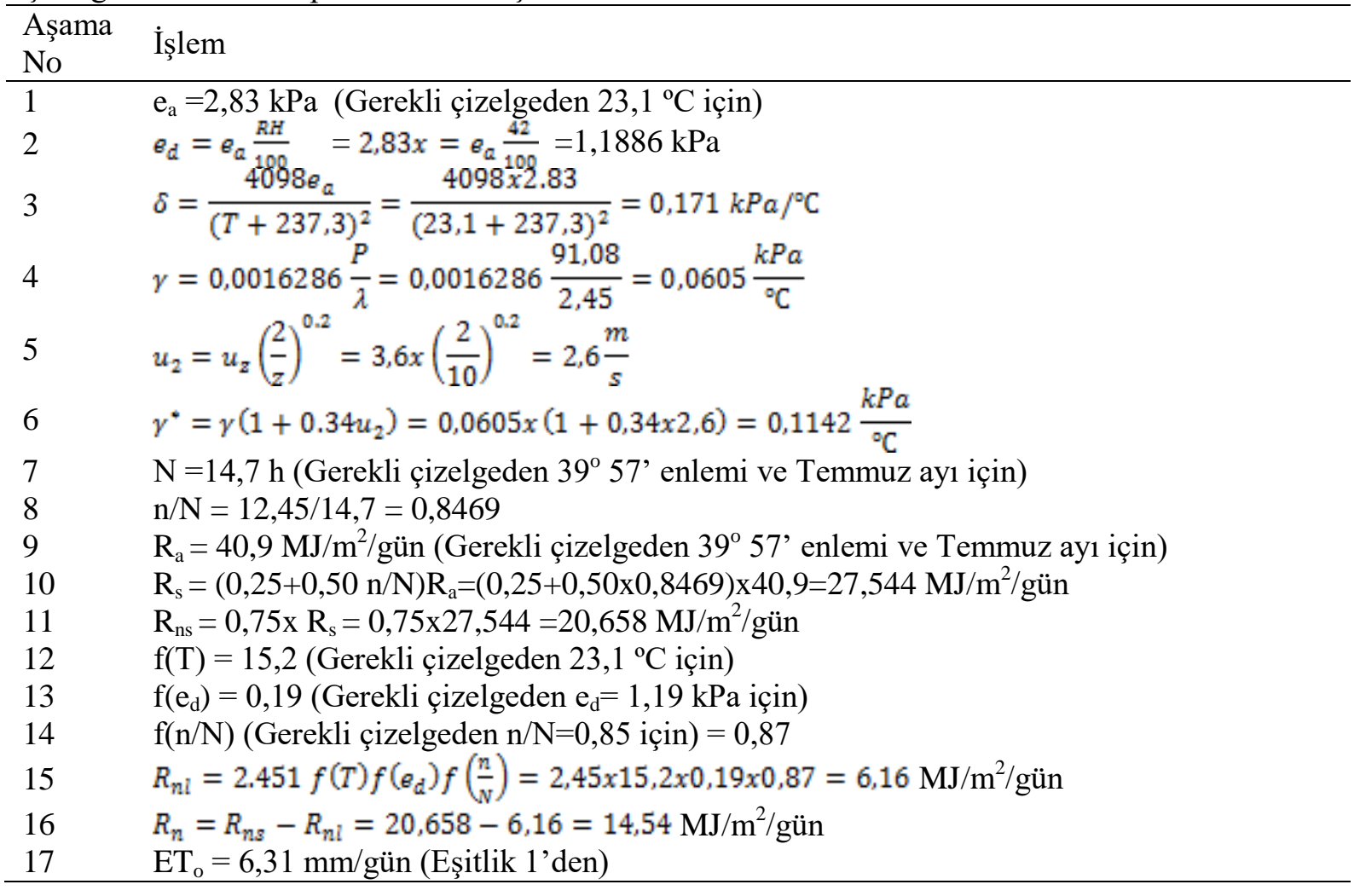

Görüldüğü gibi, Penman-Monteith yönteminin FAO modifikasyonu ile $\mathrm{ET}_{0}$ '’n elle hesaplanması oldukça zaman alıcı ve gerekli veriler için çizelgelere gereksinim vardır. Ayrıca çoğu zaman çizelge değerlerinin istenen koşullar için interpolasyonla belirlenmesi gerekir ki bu oldukça zaman alıcıdır. Geliştirilmiş olan uygulama ile ve el ile yapılan çözümde $\mathrm{ET}_{0} 6.31 \mathrm{~mm} /$ gün olarak hesaplanmıştır.

Verilerin bir araya getirilmesi, kullanım kolaylığ 1 ve yaygın olarak kullanılabilme potansiyelinin yanı sıra hesaplanan $\mathrm{ET}_{0}$ ve gereksinim duyuluyorsa hesaplama adımlarını da raporlama imkânı sağlayan uygulamanın yukarıdaki örnek çözüme ilişkin ürettiği pdf formatındaki rapor aşağıda verilmiştir (Şekil 3). Ayrıca bu raporun anında paylaşılabilme imkânı da uygulamanın sağladığı önemli avantajlardan birisi olarak karşımıza çıkmaktadır. Benzer kolaylıkları sağlamak amacıyla Kostinakis ve ark. (2011) Visual Basic programlama dilinde yine aynı yöntemi kullanarak bir yazılım geliştirmişlerdir. 


\section{EVAPOTRAN1 Uygulaması İle Referans Bitki Su Tüketimi Hesabı}

Özet:

ìl: Ankara

Enlem derecesi: 39.92077

Ortalama bağll nem: \% 42

Ortalama sıcakluk: $23.1 \mathrm{C}$

10 m'deki rüzgar hızı: $3.61 \mathrm{~m} / \mathrm{s}$

Atmosfer basinci: $91.08 \mathrm{kPa}$

Hesaplamanun yapıldığı tarih: 28:5:2021

Güneşlenme süresi (n): 12.5 saat

Doygun buhar basincl (ea): $2.86216 \mathrm{kPa}$

Gerçek buhar basıncı (es): $1.20211 \mathrm{kPa}$

Buhar basıncı eğrisinin eğimi: $0.17298 \mathrm{kPa} / \mathrm{C}$

Psikrometrik sabite: $0.06054 \mathrm{kPa} / \mathrm{C}$

2 m'deki rüzgar hızı: $2.61645 \mathrm{~m} / \mathrm{s}$

Modifiye psikrometrik sabite: $0.1144 \mathrm{kPa} / \mathrm{C}$

Olası maksimum güneşlenme (N): 14.75392 saat

Güneşlenme oranı (n/N): 0.84723

Atmosferin dış yüzeyine ulaşan radyasyon (Ra): $40.91 \mathrm{MJ} / \mathrm{m} 2 /$ gün

Yer yüzüne ulaşan kısa dalga boylu radyasyon (Rs): 27.55763 MJ/m2/gün

Kisa dalga boylu net radyasyon (Rns): 20.66823 MJ/m2/gün

Sicakllk fonksiyonu (f(T)): 15.34149

Buhar basıncı fonksiyonu (f(ed)): 0.1907

Güneşlenme oranı fonksiyonu (f(n/N)): 0.86529

Uzun dalga boylu net radyasyon (Rnl): $6.20465 \mathrm{MJ} / \mathrm{m} 2 / g u ̈ n$

Bitki yüzeyindeki net radyasyon (Rn): $14.46358 \mathrm{MJ} / \mathrm{m} 2 /$ gün

REFERANS BíTKI SU TÜKETIMI (ETo): 6.31605 mm/gün

Bu uygulama Çanakkale Onsekiz Mart Üniversitesi, Ziraat Fakültesi

Tarımsal Yapılar ve Sulama Bölümü, Dijital Tarım Laboratuvarında Geliştirilmiştir.

Ziraat Müh. Neslihan BIRCAN \& Prof. Dr. Ünal KIZIL

Şekil 3. Örnek Rapor

\section{Sonuç ve Öneriler}

Gün geçtikçe önemi artan su kaynaklarının sürdürülebilir kullanımıyla ilgili olarak teknolojinin sağladığı imkânları azami ölçüde kullanmak gerekmektedir. Bu bağlamda, tatlı su kaynaklarının en fazla kullanıldığı tarımsal üretimin sorumluluğu oldukça fazladır. Su israfının azaltılması ya da başka bir ifadeyle sulama performansının artırılabilmesi için bitkinin gereksinim duyduğu miktarda suyun doğru zamanda uygulanması çok önemlidir. Bu da bitki su tüketiminin doğru hesaplanmasıyla mümkündür. $\mathrm{Bu}$ çalışma kapsamında geliştirilen ve kullanıma sunulacak olan Android tabanlı uygulamanın bu anlamda bir gereksinimi karşılayacağı düşünülmektedir.

Çalışmada ortaya konduğu üzere geliştirilen uygulama $\mathrm{ET}_{0}$ hesaplamada kullanılan FAO Penman-Monteith yönteminin kodlanmasıyla geliştirilmiştir. Ancak en önemli özelliği veri eldesi, kullanımı ve sonuçların paylaşılmasında oldukça büyük kolaylıklar sağlamasıdır.

Masaüstü bilgisayarlarda kullanılan yazılımların aksine akıllı cihazlar üzerinde çalışan uygulamaların bir diğer avantajı da cihazın sahip olduğu diğer donanım ve özelliklerden 
faydalanabilmesidir. Bu çalışmada da kullanılan GPS sensörü, tarih ve takvim verisinin yanı sıra özellikle yeni çıkan bazı akıllı cihazlar sıcaklık, bağıl nem ve hatta basınç sensörleri de içermektedir. Dolayısıyla gerekli meteorolojik verilerin bir kısmı daha hassas olarak cihaz tarafindan sağlanarak daha doğru hesaplamalar yapmak mümkün olmaktadır. Geliştirilen uygulamanın bu sensörlerden gelen verileri kullanabilir hale getirmesi oldukça basittir.

Akıllı cihazların sunduğu bir diğer avantaj ise bluetooth, GSM şebekesi üzerinden SMS ve internet bağlantısı gibi farklı veri transfer yöntemlerine sahip olmalarıdır. Dolayısıyla farklı cihaz veya sensörlerden bu bağlantı yollarını kullanarak farklı veriler kolaylıkla elde edilebilmektedir. Örneğin bir anemometre akıllı cihaza entegre edilerek rüzgar hızı ile ilgili daha gerçekçi değerler elde edilebilmektedir. $\mathrm{Bu}$ ise geliştirilen uygulamaya bir dinamizm kazandırabilmektedir. Dolayısıyla gerekli veriler sadece API bağlantısına bağımlı kalmadan cihaz dışı sensörlerden de elde edilebilmektedir.

Akıllı cihazın internet bağlantısı kullanılarak cihazın sensörlerinden, harici sensörlerden ya da API bağlantısıyla elde edilmiş meteorolojik veriler bulut sistemi üzerinde kolaylıkla depolanabilmektedir. Örneğin bu yöntemlerle elde edilen meteorolojik veriler Google Drive üzerinde bulunan Google Sheets ortamında MS Excel formatında istenilen s1klikta otomatik olarak depolanabilmekte ve ileride başka amaçlarla kullanılabilmektedir.

Uygulamanın yukarıda sözü edilen yöntemlerle veri alabilmesinin yanı sıra yine aynı kanallarla komut ve bilgi göndermesi mümkündür. $\mathrm{Bu}$ ise geliştirilen uygulamanın aslında sulama çalışmalarında bir otomasyon aracı olarak kullanılabilmesini de sağlamaktadır. Bu bağlamda ileriye yönelik olarak harici sensörlerle entegre edilmiş olan basit ama fonksiyonel bir otomasyon uygulamasının geliştirilmesi planlanmaktadır. Bu amaçla, $\mathrm{ET}_{0}$ haricinde gerçek bitki su tüketimi hesabı da uygulamaya ilave edilecektir. Bunun için elbette ki birçok bitki katsayısının uygulamaya tanıtılması gerekecektir. İleriki çalışmalarımızda ayrıca elde edilecek meteorolojik verilerle birlikte sulama gereksinimi hesaplama sonuçlarının depolandığı bulut tabanlı bir veri tabanın geliştirilmesi hedeflenmektedir.

Not: Bu makale ÇOMÜ Fen Bilimleri Enstitüsü Tarımsal Yapılar ve Sulama Anabilim Dalı Öğrencisi Neslihan Bircan'ın "Referans Evapotranspirasyon Hesabında Kullanılacak Android Tabanlı Bir Uygulamanın Geliştirilmesi” isimli Yüksek Lisans tez çalışmasından türetilmiştir.

\section{Kaynaklar}

Allen, R.G., Pereira L.S., Raes D., and Smith M., 1998. Crop evapotranspiration: guidelines for computing crop water requirements. Irrigation and Drainage. pp. 56, FAO, Rome, Italy.

Allen, R.G., Smith, M., Perkier, A., Pereira, L.S., 1994. An Update forthe Definition of Reference Evapotranspiration, ICID Bull.43(2): 1-34.

Anonim, 2021. App Inventor. Vikipedi. Özgür Ansiklopedi. Erişim tarihi: 31.05.2021. url://tr.wikipedia.org/w/index.php?title=App_Inventor\&oldid=25093866.

Ballesteros, R., Ortega, J.F., Moreno, M.A., 2016. FORETo: New software for reference evapotranspiration

Burnette, E., 2010. Hello, Android: Introducing Google's mobile development platform, 3rd Edition. The Pragmatic Bookshelf. pp.33.

FAO, 2009. Cropwat 8.0 for windows user guide. Rome, Italy forecasting. Journal of Arid Environments. 124: 128-141.

Gocic, M., Trajkovic, S., 2010. Software for estimating reference evapotranspiration using limited weather data. Computers and Electronics in Agriculture, 71:158-162.

Holla, S., Katti, M.M., 2012. Android based mobile application development and its security. International Journal of Computer Trends and Technology. 3(3): 486-490

Jensen, M.E., 1968. Water consumption by agricultural plants. Water deficits and plant growth, Kozlowski TT ed., Academic, New York, 2: 1-45.

Jensen, M.E., Wright, J.L., and Pratt, B.J., 1971. Estimating soil moisture depletion from climate, Crop, And Soil Data. Trans. ASAE. 14(5): 954-959.

Karaca, C., Büyüktaş, D., Tekelioğlu, B., 2017a. Kıyas bitki su tüketiminin (ETo) hesaplanması amaciyla bilgisayar yazılımlarının karşılaştırması. Gaziosmanpaşa Bilimsel Araştırma Dergisi. 6: 118-128.

Karaca, C., Büyüktaş, D., Tekelioğlu, B., Baştuğ, R., 2017b. Kıyas bitki su tüketiminin hesaplanmasında kullanılan eşitliklerin değerlendirilmesi, Akademia Mühendislik ve Fen Bilimleri Dergisi. 1: 144-161. 
Kostinakis, K., Xystrakis, F., Theodoropoulos, K., Stathis, D., Eleftheriadou, E., Matzarakis, A., 2011. Estimation of reference potential evapotranspiration with focus on vegetation science-the EmPEst software. Journal of Irrigation and Drainage Engineering. 137(9): 616-619.

Monteith, J.L., 1965. Evaporation and environment. Symp. Soc. Exp. Biol. 19: 205-234.

Penman, H.L., 1948. Natural evaporation from open water, bare soil and grass. Proc. Royal Soc. London, Mathematical and Physical Sciences. 193: 120-145.

Pocatilu P., 2011. Android applications security. Informatica Economica. 15(3):163-171.

Raes, D., Geerts, S., Kipkorir, E., Wellens, J., Sahli, A., 2006. Simulation of yield decline as a result of water stress with a robust soil water balance model. Agricultural Water Management. 81: 335-357

Raes, D., Lemmens, H., Van Aelst, P., Vanden Bulcke, M., Smith, M., 1988. IRSIS-Irrigation scheduling information system, vol. 1. Manual. K.U.Leuven, Dep. Land Management, Reference Manual 3.

Steduto, P., Hsiao, T. C., Raes, D., Fereres, E., 2009. AquaCrop-The FAO crop model to simulate yield response to water: I. concepts and underlying principles. Agron J 101. 